\title{
Process Variables and the Performance of Soybean-oil Rosin-based Polyester as an Internal Sizing Agent
}

\author{
Yazhou Xu, a,b Yuxiang Chen, a,b,c,d,* Zhendong Zhao, ${ }^{\text {a,b,c }}$ and Shichao Xu ${ }^{\text {a,b,c }}$ \\ Soybean-oil rosin-based polyester (SRP) has many uses in papermaking, \\ but its performance as an internal sizing agent differs depending on the \\ circumstances. In this study, a comprehensive laboratory approach was \\ used to investigate the process variables affecting SRP application. Five \\ levels of $\operatorname{SRP}(0.5 \%, 1.0 \%, 1.5 \%, 2.0 \%$, and $2.5 \%)$, five levels of aluminum \\ sulfate $(0.5 \%, 1.0 \%, 1.5 \%, 2.0 \%$, and $2.5 \%)$, and five levels of cationic \\ polyacrylamide $(0.05 \%, 0.1 \%, 0.15 \%, 0.2 \%$, and $0.25 \%)$ were considered \\ to determine the best process variables within a $\mathrm{pH}$ range of 5.0 to 9.0 . \\ Aspects that were considered included the mechanical properties (tensile, \\ burst, and tear indices), water resistance (Cobb test, dynamic contact \\ angle test, and scanning electron microscopy), and chemical usage \\ (economical and environmentally friendly procedures). The optimum \\ conditions based on these factors were 1.0\% SRP, 1.0\% aluminum \\ sulfate, and $0.15 \%$ cationic polyacrylamide levels at a $\mathrm{pH}$ of 7.0 . The \\ results showed that in the optimal sizing system, $15 \%$ calcium carbonate \\ can be tolerated.
}

Keywords: Internal sizing; Process variables; Soybean oil; Rosin; Polyester

Contact information: a: Institute of Chemical Industry of Forest Products, CAF, National Engineering Lab for Biomass Chemical Utilization, Key Lab of Chemical Engineering of Forest Products, National Forestry and Grassland Administration, Key Lab of Biomass Energy and Material, Nanjing 210042, Jiangsu, China; b: Co-Innovation Center of Efficient Processing and Utilization of Forest Resources, Nanjing Forestry University, Nanjing 210037, Jiangsu, China; c: Research Institute of Forestry New Technology, CAF, Beijing 100091, China; d: Jiangsu Qianglin Bio-energy and Bio-materials Limited Company, Liyang 213364, Jiangsu, China; *Corresponding author: cyxlhs@126.com

\section{INTRODUCTION}

Paper has a strong tendency to absorb water, especially paper that contains hemicellulose, with poor mechanical properties (Katz et al. 2003). To mitigate this limitation and increase the water repellency of paper, hydrophobic sizing is performed for most paper grades, especially for writing and packaging papers.

Soap rosin is a sizing agent with a long history of success in papermaking and is usually suited for a $\mathrm{pH}$ less than 6.5 (Rahmaninia et al. 2016). When paper is sized under neutral to alkaline conditions, the equipment is not corroded, the paper is not easily hydrolyzed, and calcium carbonate can be used as a filler. Changing the papermaking process to favor neutral-to-alkaline conditions puts pressure on the industry to seek new sizing agents in this respect. Alkylketene dimer (AKD) was the first agent to be used for this process (Varshoei et al. 2014). As a reactive sizing agent, AKD is bonded to paper by esterification of a quaternary lactone with a hydroxyl group of cellulose in the paper. It is hydrophobic because of hydrophobic hydrocarbons and has advantages such as operation without alum and sufficient sizing degrees for paper at low addition levels (Lindström and Larsson 2008). However, some problems have been associated with the use of synthetic 
sizing agents. These include the low friction coefficient of AKD-sized papers, size reversion, deposit formation on the paper machine and press felts, relatively high costs, and insufficient sizing effect in paper when evaluated at the reel of the paper machine (Kitaoka et al. 1997; Wu et al. 1997).

Because of its nonpolar, tricyclic molecular structure, rosin has excellent water resistance, which is critical for its use in internal sizing (Wang et al. 1999). Rosin sizing agents are usually inexpensive, user friendly, and tolerant of other wet-end additives. Also they have a longer shelf life than other sizing agents (e.g., AKD). Because of these advantages, technical teams in many papermaking mills want to switch to neutral-toalkaline-pH papermaking systems without abandoning rosin-based sizing.

Consequently, modified rosin sizes have attracted interest in the field (Ozaki and Sawatari 1997; Kitaoka et al. 2000; Matsushita et al. 2004). Alternatively, some researchers have investigated sizing strategies with esterified rosins (Wang et al. 2003; Liu et al. 2006; Hubbe 2007; Yao et al. 2011). Compared with the conventional anionic and dispersed rosin sizing agents, the rosin-ester sizing agent remarkably improves the stability of rosin particles in alkaline pulp suspensions. Therefore, such products can be used as an internal sizing agent for alkaline papermaking (Wang and Tanaka 2000; Wang et al. 2000). Although our information about different aspects of rosin application in paper mills $(\mathrm{pH}$ adjustment, tolerance assessment, optimum chemical dosages, etc.) has considered many issues (Seppänen et al. 2000; Kitaoka et al. 2001; Mattsson et al. 2002; Hamzeh et al. 2008), combining rosin-based sizing agents and AKD seems to need more attention, because of lacking research to try to combine the advantages of AKD and rosin. Some of these areas, such as retention aid dosages, $\mathrm{pH}$ adjustment, and tolerance assessment, can provide a proper lead for optimizing the process.

Soybean oil has a similar hydrophobic chain structure to AKD. This study attempted to combine the advantages of rosin and AKD and prepared a soybean-oil rosinbased polyester (SRP) sizing agent that can be used for neutral sizing. This study also explored process variables that facilitate the development of an SRP sizing agent in the papermaking field.

\section{EXPERIMENTAL}

\section{Materials}

Bleached wood pulp (50\% conifer and 50\% broadleaf ) with a beating degree of 34 ${ }^{\circ}$ SR was kindly provided by Anhui Baiyi Biological Technology Co., Ltd. (Anhui, China). Wetland rosin was a commercial product from Guangxi, China. Soybean oil (The oleic acid mass fraction is $51.0 \%$, the linoleic acid mass fraction is $28.0 \%$, and the palmitic acid mass fraction is $11.9 \%$, the acid value is $0 \mathrm{mg} / \mathrm{g}$, and the hydroxyl value is $22.4 \mathrm{mg} / \mathrm{g}$ ) and maleic anhydride (99\%) were from Shanghai Lingfeng Chemical Reagent Co., Ltd. (Shanghai, China). Glycerol (99\%) and calcium carbonate $\left(\mathrm{CaCO}_{3}\right)$ were purchased from Aladdin Industrial Corporation (Shanghai, China). Ethoxylated nonylphenol sulfosuccinic acid half ester disodium salt (40\%) was supplied by Shanghai Jinjinle Industry Co., Ltd. (Shanghai, China). Cationic polyacrylamide (CPAM) (molecular weight of 6 million $\mathrm{g} / \mathrm{mol}$, charge density of $1.95 \mathrm{mmol} / \mathrm{g}$ ) was from Yixing Bluwat Chemicals Co., Ltd. (Yixing, Jiangsu, China). Aluminum sulfate $\left(\mathrm{Al}_{2}\left(\mathrm{SO}_{4}\right)_{3}\right)$ and other chemicals were analytically pure reagents. All materials were used without further purification. 

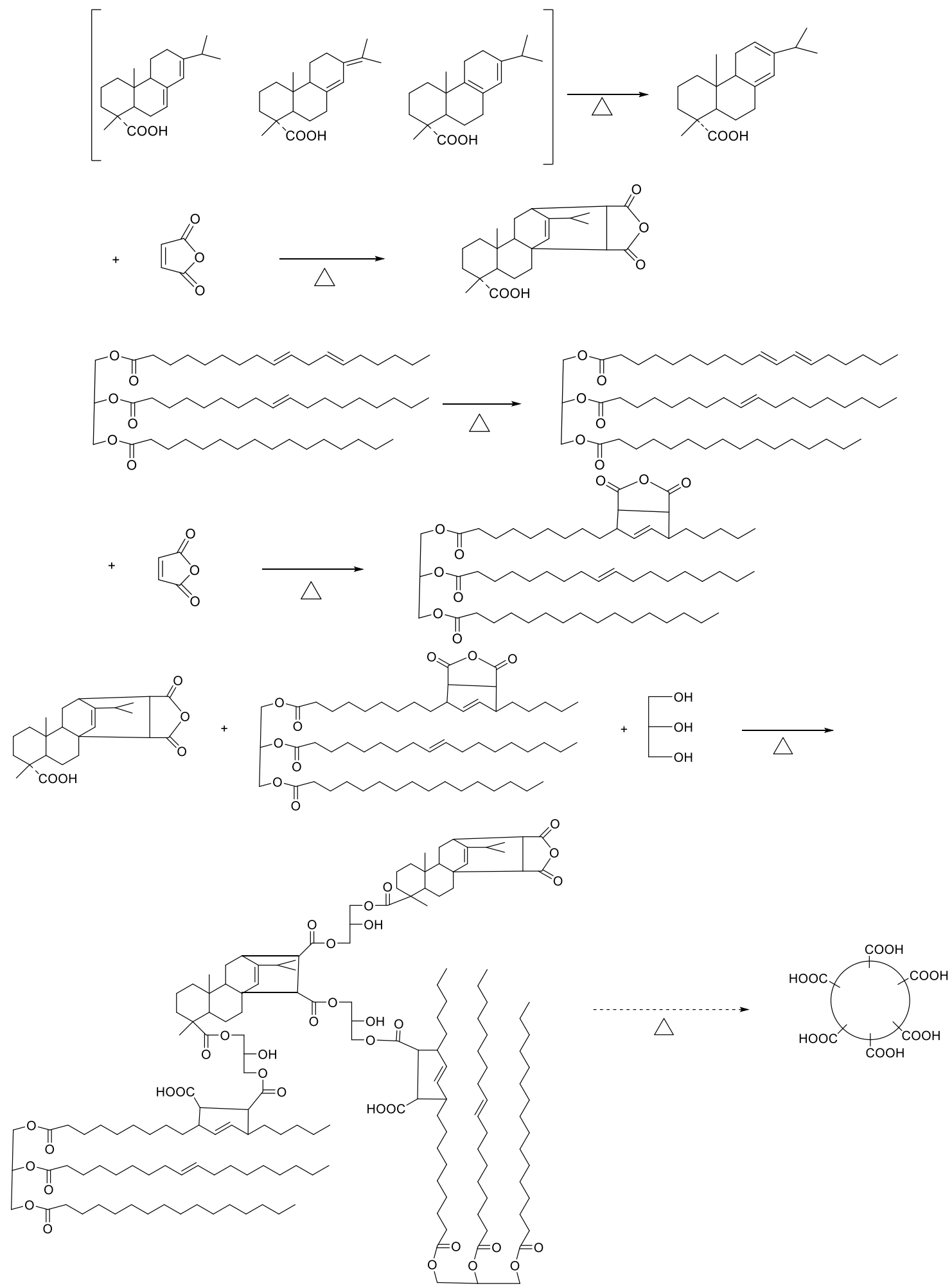

Fig. 1. The synthesis route of SRP

Preparation of the SRP sizing agent

According to $\mathrm{Xu}$ et al. (2019), into a four-necked flask equipped with a stirring device, $50 \mathrm{~g}$ of rosin, $20 \mathrm{~g}$ of soybean oil, and $10 \mathrm{~g}$ of maleic anhydride were placed and 
protected with nitrogen. Maleopimaric acid and the anhydride adduct of soybean oil were obtained by reacting at $185{ }^{\circ} \mathrm{C}$ for $2 \mathrm{~h}$. Then $2.5 \mathrm{~g}$ of glycerol was added to make the material carboxy-carboxyl ratio equal to 0.25 (the amount of carboxyl groups in the material can be obtained by measuring the acid value, thereby obtaining the ratio of the amount of the material hydroxyl group to the carboxyl group). After each reaction at 210 ${ }^{\circ} \mathrm{C}$ and $225^{\circ} \mathrm{C}$ for $1 \mathrm{~h}$, soybean-oil-rosin-based polyester SRP was prepared by heating to $250{ }^{\circ} \mathrm{C}$ for $3 \mathrm{~h}$. Figure 1 shows the synthesis route of SRP.

The SRP was first melted at $120{ }^{\circ} \mathrm{C}$. Ethoxylated nonylphenol sulfosuccinic acid half ester disodium salt, preheated to $90{ }^{\circ} \mathrm{C}$, was introduced within 10 min with gentle stirring to obtain a homogenous water-in-oil emulsion. The emulsion was inverted to an oil-in-water emulsion by quickly adding $90{ }^{\circ} \mathrm{C}$ deionized water at a stirring speed of 1000 rpm. The emulsion was then cooled to the ambient temperature in a cold water bath. The SRP latex was obtained, and its physical and chemical properties were measured (Table 1).

Table 1. Physical and Chemical Properties of SRP Latex

\begin{tabular}{|c|c|}
\hline Property & Description or Value \\
\hline Appearance & Milky bluish-white liquid \\
\hline $\mathrm{pH}$ & 5 to 6 \\
\hline Viscosity & $<100 \mathrm{mPa} \cdot \mathrm{s}$ \\
\hline Particle size & $0.2 \mu \mathrm{m}$ \\
\hline Solid content & Approximately $25 \%$ \\
\hline
\end{tabular}

\section{Methods}

\section{Characterization}

Fourier transform infrared (FTIR) spectroscopy (Vertex 70; Bruker Optik GmbH, Ettlingen, Germany) analyses of samples were carried out by using compressed pellets of $\mathrm{KBr}$ with SRP. All FTIR spectra were recorded using absorbance mode in the wavenumber range of $500 \mathrm{~cm}^{-1}$ to $4000 \mathrm{~cm}^{-1}$. The hydrodynamic diameter and size distribution were measured by dynamic light scattering (Zetasizer 3000; Malvern Instruments, Malvern, UK) three times to yield an average.

The apparent viscosity of the latexes was determined using a rotational viscometer (NDJ-5S; Shanghai Geological Instrument Research Institute, Shanghai, China). Droplets having a volume of $5 \mu \mathrm{L}$ of deionized water were dropped onto the surface of the paper, and the water contact angle for the sized paper was measured with an optical contact angle apparatus (DSA 100; Kruss Scientific Instruments, Hamburg, Germany) equipped with a video measuring system and high-resolution CCD camera. The surface morphology of the sized paper coated with gold was observed using a scanning electron microscope (S-3400I, Hitachi, Tokyo, Japan).

\section{Internal sizing method}

Handsheets with a basis weight of $70 \mathrm{~g} / \mathrm{m}^{2}$ were made using a CHCP-02 round sheet former (Jinan Shengtuo Mechanical and Electrical Equipment Co., Ltd., Jinan, China.). To prepare sized handsheets, $1.0 \%$ SRP sizing agent (relative to the absolute dry pulp mass) was added to a $0.5 \%$ pulp suspension, followed by $1.0 \% \mathrm{Al}_{2}\left(\mathrm{SO}_{4}\right)_{3}$ (relative to the absolute dry pulp mass) and $0.15 \%$ CPAM (relative to the absolute dry pulp mass) at $\mathrm{pH} 7.0$ (adjusted with $0.15 \mathrm{~mol} / \mathrm{L} \mathrm{HCl}$ and $0.15 \mathrm{~mol} / \mathrm{L} \mathrm{NaOH}$ ). The handsheets were dried in a CHGZ-01 dryer (Jinan Shengtuo Mechanical and Electrical Equipment Co., Ltd., 
Jinan, China.) at $105^{\circ} \mathrm{C}$. The paper was allowed to dry at $23{ }^{\circ} \mathrm{C}$ and $50 \%$ relative humidity for over $24 \mathrm{~h}$ until further analysis; then, its properties were measured (Table 2).

Table 2. Measured Physical Properties and Measurement Methods of Prepared Sheets

\begin{tabular}{|c|c|}
\hline Property & Standard \\
\hline Basis weight $\left(\mathrm{g} / \mathrm{m}^{2}\right)$ & ISO 536 (2012) \\
\hline Cobb-60 & ISO 535 (2014) \\
\hline Tensile index & ISO 1924-2 (2008) \\
\hline Burst index & ISO 2758 (2014) \\
\hline Tear index & ISO 1974 (2012) \\
\hline Contact angle & Instrument manual \\
\hline
\end{tabular}

\section{RESULTS AND DISCUSSION}

\section{FTIR Analysis}

The polyester was characterized by FTIR spectroscopy. The specific adsorptions of the main functional groups are shown in Fig. 2. The absorption peak at $1760 \mathrm{~cm}^{-1}$ corresponds to - $\mathrm{COO}-$, which suggests that the reaction produced esters. No hydroxyl absorption peak appeared at $3490 \mathrm{~cm}^{-1}$, indicating that the glycerin in the reaction completely reacted. The absorption peak at $1710 \mathrm{~cm}^{-1}$ was due to $-\mathrm{COOH}$. These results imply that SRP with a terminal carboxyl group was obtained.

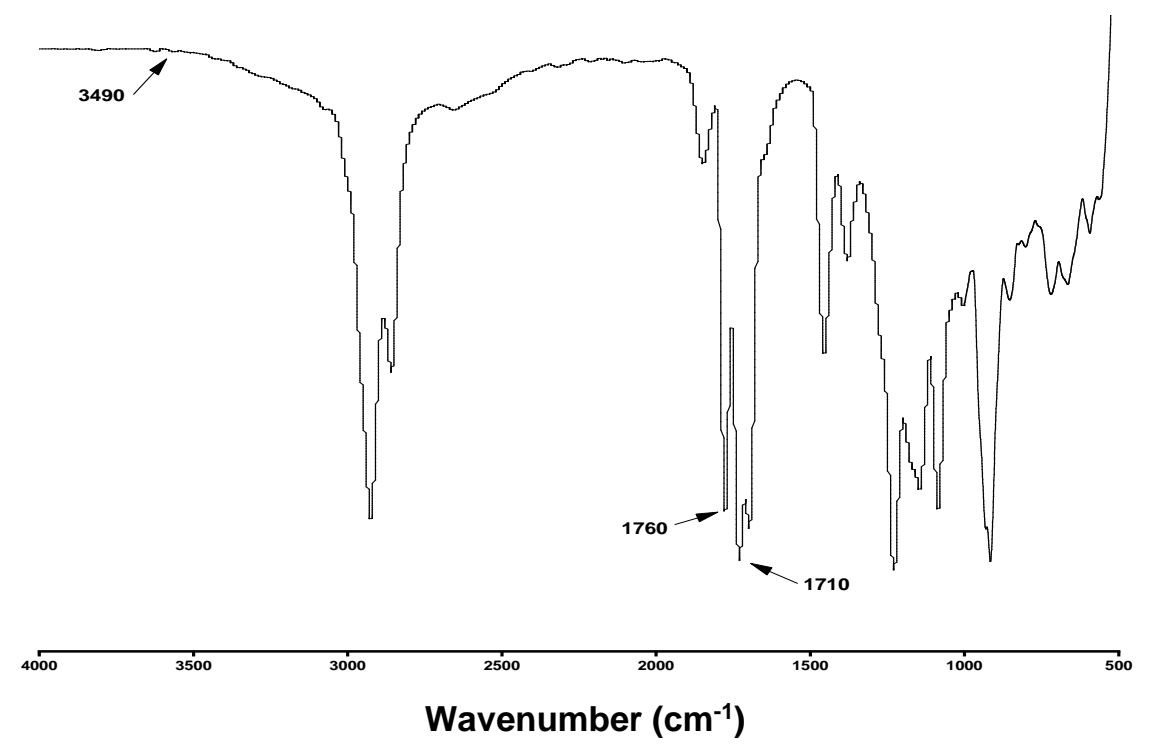

Fig. 2. FTIR spectrum of the SRP

\section{Particle Size Distribution of SRP Latex}

As the most important characterization parameter of the SRP latex, the particle size of the emulsion directly affects the emulsion's sizing effect and has an important influence on its stability. 
As shown in Fig. 3, the polydispersity index of the SRP latex was 0.251 , indicating that the particle size distribution of the latex was uniform, and the average particle size was $0.224 \mu \mathrm{m}$. The average diameter of commercially available sizing agent latex is less than $0.4 \mu \mathrm{m}$, and SRP latex can meet the requirements for practical use in terms of particle size.

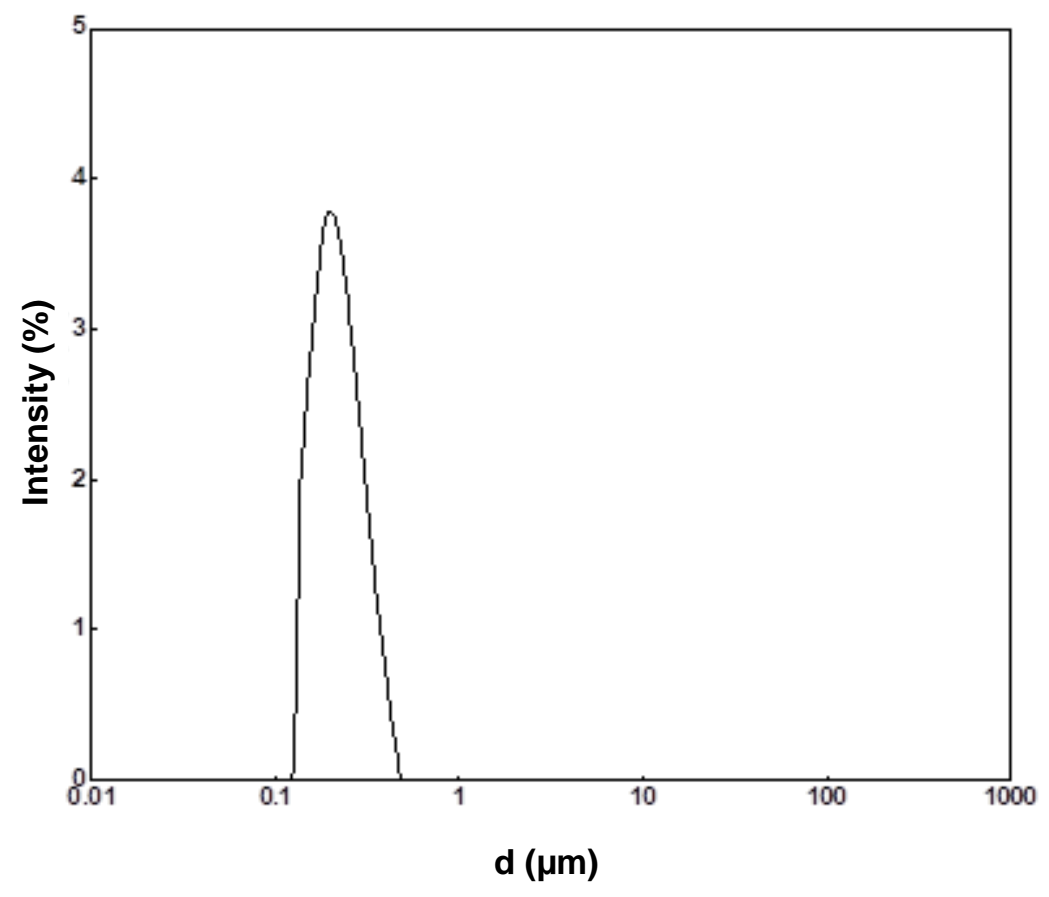

Fig. 3. Particle size distribution of SRP latex

\section{Effect of SRP Dosage on Water Resistance}

As shown in Fig. 4, under the conditions of $1.0 \% \mathrm{Al}_{2}\left(\mathrm{SO}_{4}\right)_{3}$ and $0.15 \% \mathrm{CPAM}$ at $\mathrm{pH} 7.0$, the Cobb-60 of the handsheet decreased when increasing the SRP dosage from $0.5 \%$ to $2.5 \%$. When the SRP dosage reached $1 \%$, the rate of increase of the sizing degree markedly decreased. This was because the adsorbed amount of the polyester on the surfaces of the paper fibers increased with the increasing SRP sizing agent dosage, and the sizing degree correspondingly increased. However, the adsorption of the polyester particles to the fibers was nearly saturated when the SRP sizing agent dosage was increased to a certain value.

When increasing the amount of glue beyond this point, the fiber adsorption of polyester particles did not increase much, and the sizing degree slowly changed. Based on the conditions of the fiber, precipitant, and retention aid, the sizing degree could be effectively increased without simply increasing the amount of sizing agent. The appropriate sizing agent dosage should be selected based on the sizing cost and the sizing degree. 


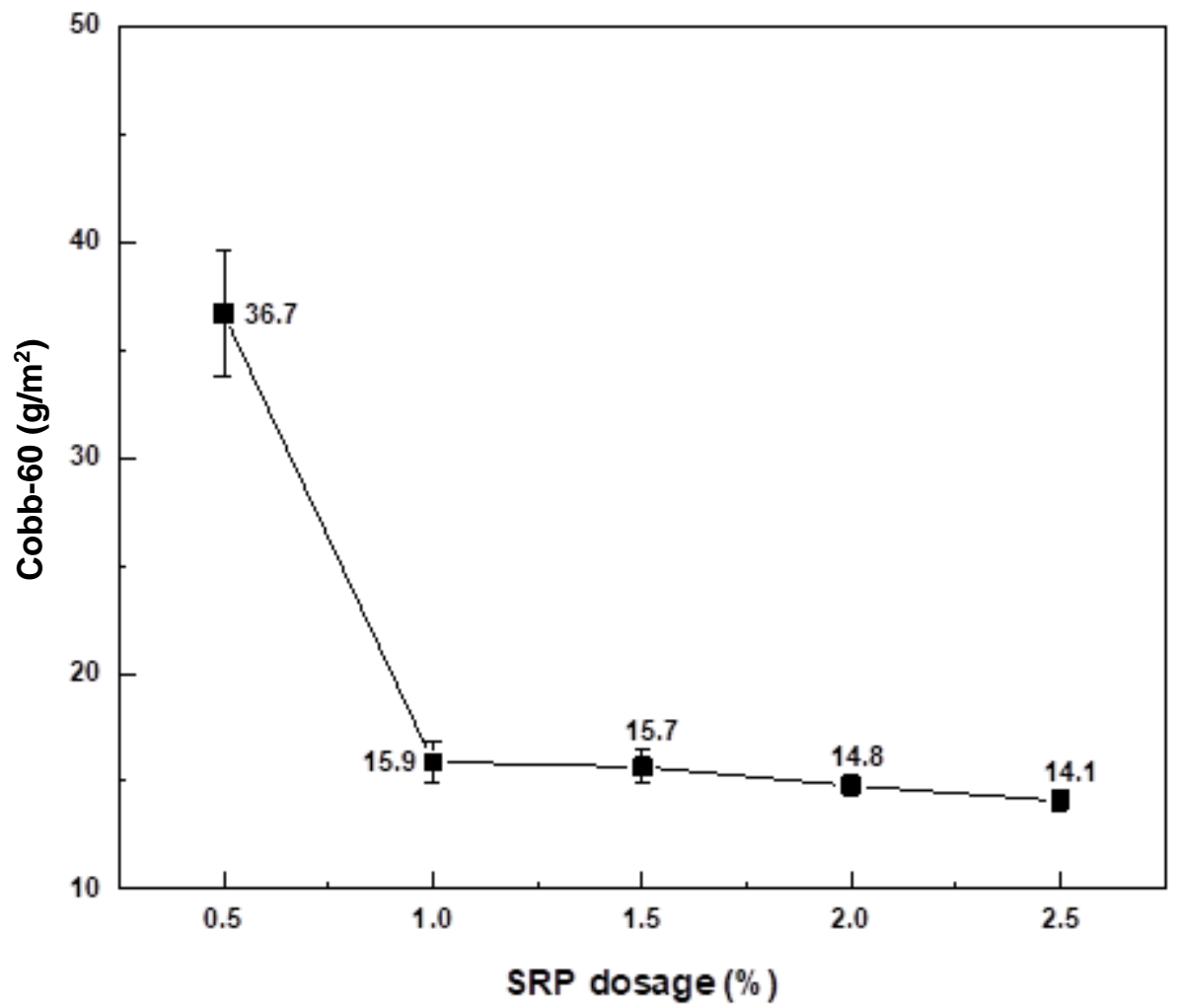

Fig. 4. Effect of SRP dosage on water resistance

\section{Effect of SRP Dosage on the Mechanical Properties}

As shown in Table 3, under the conditions of $1.0 \% \mathrm{Al}_{2}\left(\mathrm{SO}_{4}\right)_{3}$ and $0.15 \% \mathrm{CPAM}$ at $\mathrm{pH} 7.0$, when decreasing the SRP dosage from $0.5 \%$ to $2.5 \%$, the bursting index decreased $25.6 \%$; the tear index decreased $8.2 \%$; and the tensile index decreased $18.9 \%$. This was probably because the tensile strength and the burst strength are mainly affected by the fiber bonding force and the average fiber length, whereas the main factor influencing the tear strength is the average fiber length. In the sizing process, the polyester granules mainly affected the bonding between the fibers, and they had no effect on the average length of the fibers. Consequently, the tensile strength and the breaking resistance were greatly decreased, while the tearing degree decreased less.

Table 3. Effect of SRP Dosage on the Mechanical Properties

\begin{tabular}{|c|c|c|c|}
\hline SRP Dosage (\%) & $\begin{array}{c}\text { Burst Index } \\
\left(\mathrm{kPa} \cdot \mathrm{m}^{2} / \mathrm{g}\right)\end{array}$ & $\begin{array}{c}\text { Tear Index } \\
\left(\mathrm{mN} \cdot \mathrm{m}^{2} / \mathrm{g}\right)\end{array}$ & $\begin{array}{c}\text { Tensile Index } \\
(\mathrm{N} \cdot \mathrm{m} / \mathrm{g})\end{array}$ \\
\hline 0.5 & 3.01 & 17.03 & 45.66 \\
\hline 1.0 & 2.95 & 16.51 & 43.06 \\
\hline 1.5 & 2.73 & 16.33 & 41.23 \\
\hline 2.0 & 2.52 & 15.95 & 38.55 \\
\hline 2.5 & 2.24 & 15.63 & 37.02 \\
\hline
\end{tabular}


Considering all aspects, such as avoiding superfluous chemical usage and the mechanical properties, the use of $1.0 \%$ SRP sizing agent was selected as the best treatment option.

\section{Effect of Aluminum Sulfate Dosage on Water Resistance}

Aluminum sulfate $\left(\mathrm{Al}_{2}\left(\mathrm{SO}_{4}\right)_{3}\right)$ has important roles in internal sizing, affecting the retention of the sizing agent, the attachment of the sizing agent to the fibers, and the anchoring and orientation of the sizing agent molecules. Figure 5 shows that for $1.0 \%$ SRP sizing agent and $0.15 \% \mathrm{CPAM}$ at $\mathrm{pH} 7.0$, the water resistance effects of $\mathrm{Al}_{2}\left(\mathrm{SO}_{4}\right)_{3}$ dosages ranged from $0.5 \%$ to $2.5 \%$. With increasing $\mathrm{Al}_{2}\left(\mathrm{SO}_{4}\right)_{3}$, the Cobb-60 values decreased at first and then increased slightly, and the sizing degree of the paper increased and then decreased slightly. This was because a certain amount of sizing agent only combined with a certain amount of aluminum sulfate; therefore, the optimum amount of aluminum sulfate was $1.0 \%$.

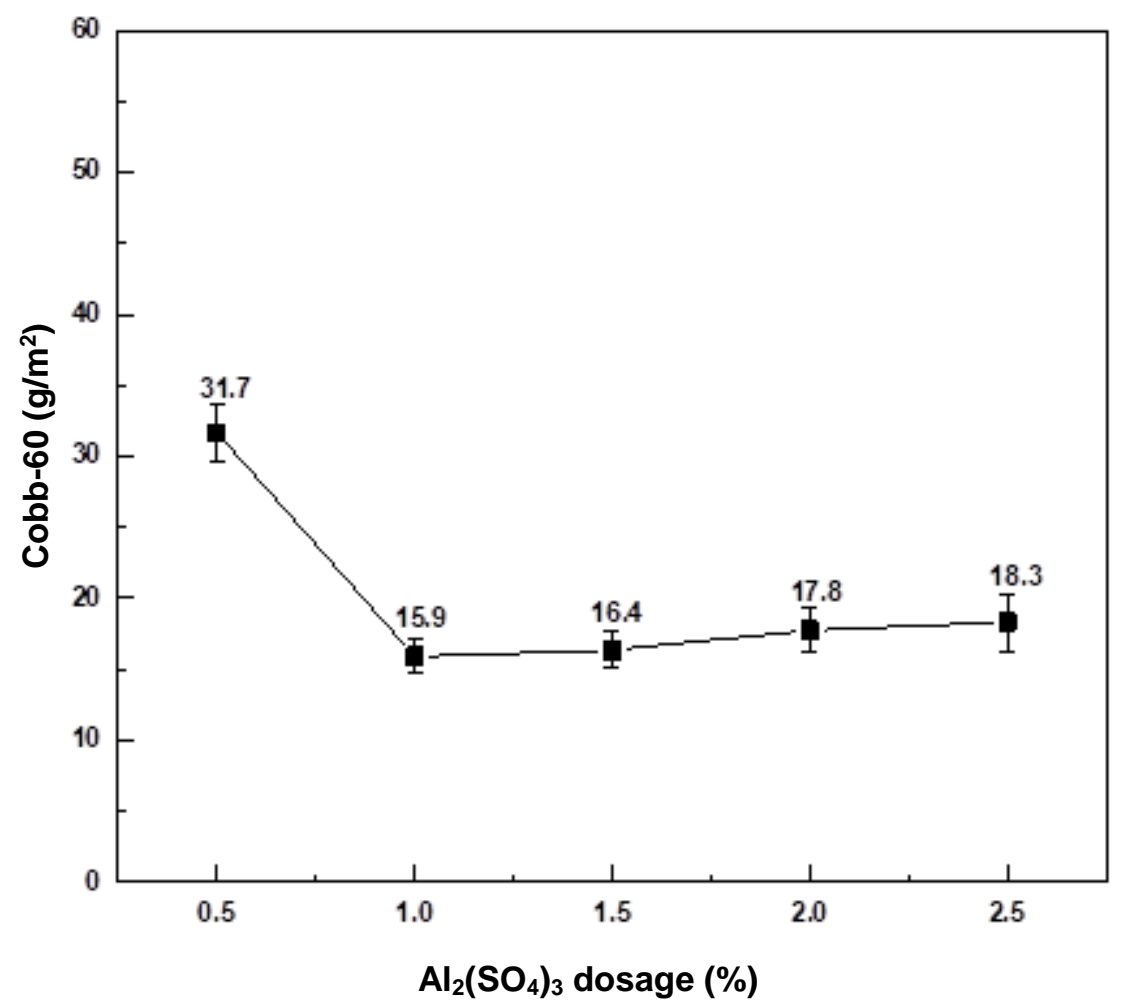

Fig. 5. Effect of $\mathrm{Al}_{2}\left(\mathrm{SO}_{4}\right)_{3}$ dosage on water resistance

\section{Effect of CPAM Dosage on Water Resistance}

Cationic polyacrylamide mainly achieves the retention effect by flocculation. It can resist the effects of fluid shearing forces to a certain extent, and it has good effects on sizing. However, if the amount of CPAM is too great, flocculation also occurs, resulting in uneven paper sheets; hence, the amount of CPAM is also an important parameter. 
As shown in Fig. 6, with $1.0 \% \mathrm{Al}_{2}\left(\mathrm{SO}_{4}\right)_{3}$ and $1.0 \%$ SRP sizing agent at $\mathrm{pH} 7.0$, the CPAM dosage was changed from $0.05 \%$ to $0.25 \%$. As the amount of CPAM increased, the Cobb-60 values decreased and then increased, and the sizing degree of the paper increased and then decreased. The decrease in sizing at the higher dosage levels might have been due to flocculation. Therefore, the optimum amount of CPAM was judged to be $0.15 \%$.

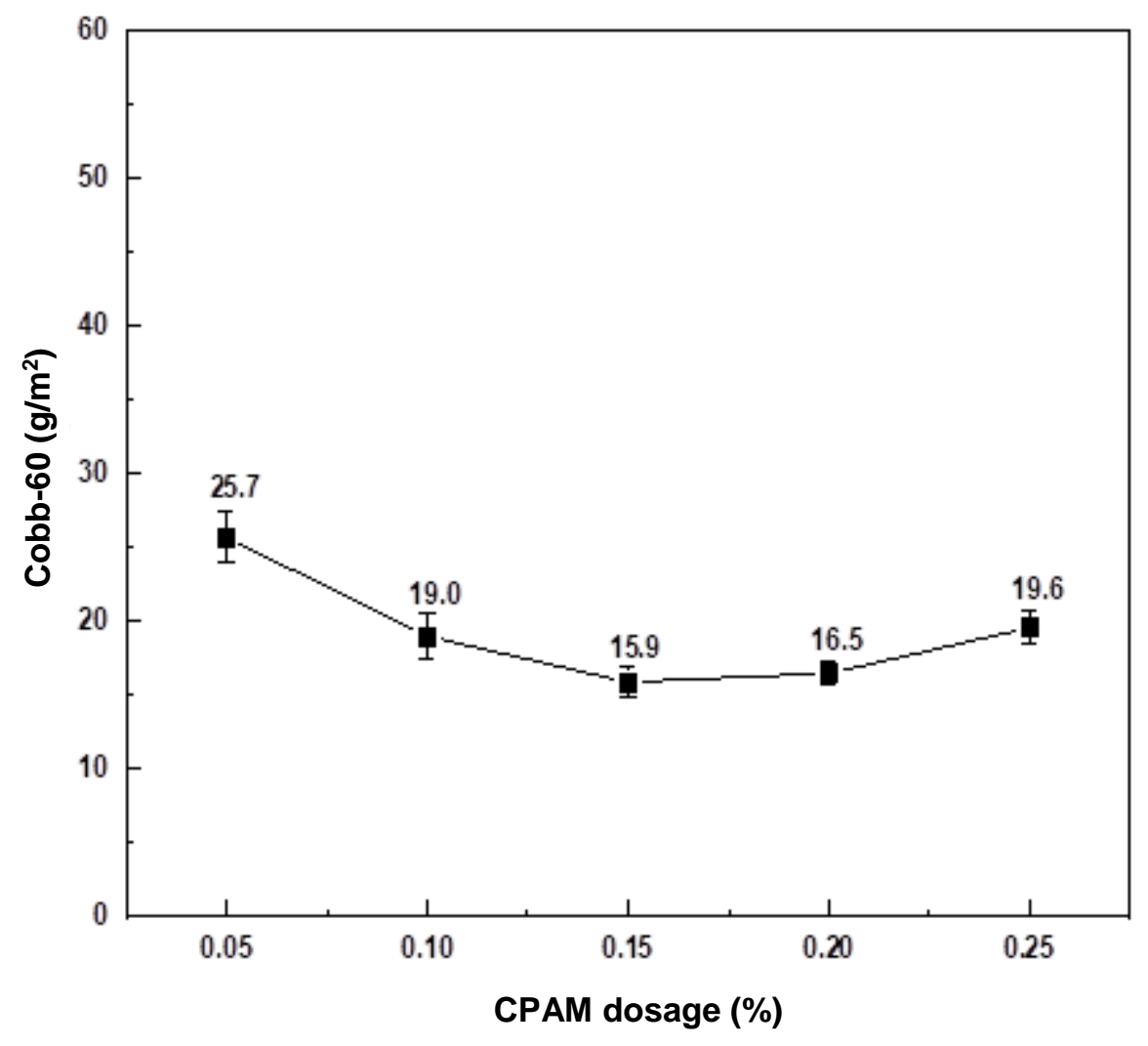

Fig. 6. Effect of CPAM dosage on water resistance

\section{Effect of pH on Water Resistance}

As shown in Fig. 7, with $1.0 \%$ SRP sizing agent, $1.0 \% \mathrm{Al}_{2}\left(\mathrm{SO}_{4}\right)_{3}$, and $0.15 \%$ CPAM, the $\mathrm{pH}$ adjusted with $0.15 \mathrm{~mol} / \mathrm{L} \mathrm{HCl}$ and $0.15 \mathrm{~mol} / \mathrm{L} \mathrm{NaOH}$ was changed from 5.0 to 9.0. Cobb-60 remained mostly unchanged for $\mathrm{pH} \leq 7.0$, and the polyester sizing agent Cobb-60 value was $15.9 \mathrm{~g} / \mathrm{m}^{2}$ at a $\mathrm{pH}$ of 7.0. This result indicates that the SRP sizing agent can fully meet the requirements of neutral sizing. As the $\mathrm{pH}$ exceeded 7.0, Cobb-60 began to increase, and the sizing degree began to decrease. The first possible reason for this result is that aluminum sulfate began to exist as precipitated aluminum hydroxide, gradually reducing the effect of eliminating anionic impurities and joining the fibers to the polyester particles. Secondly, the $\mathrm{pH}$ affected the degree of ionization of the rosin acid carboxyl group in the polyester. As the $\mathrm{pH}$ increased, the degree of ionization of the carboxyl group also increased, along with the hydrophilicity. Therefore, the sizing degree began to decrease with $\mathrm{pH}>7.0$. 


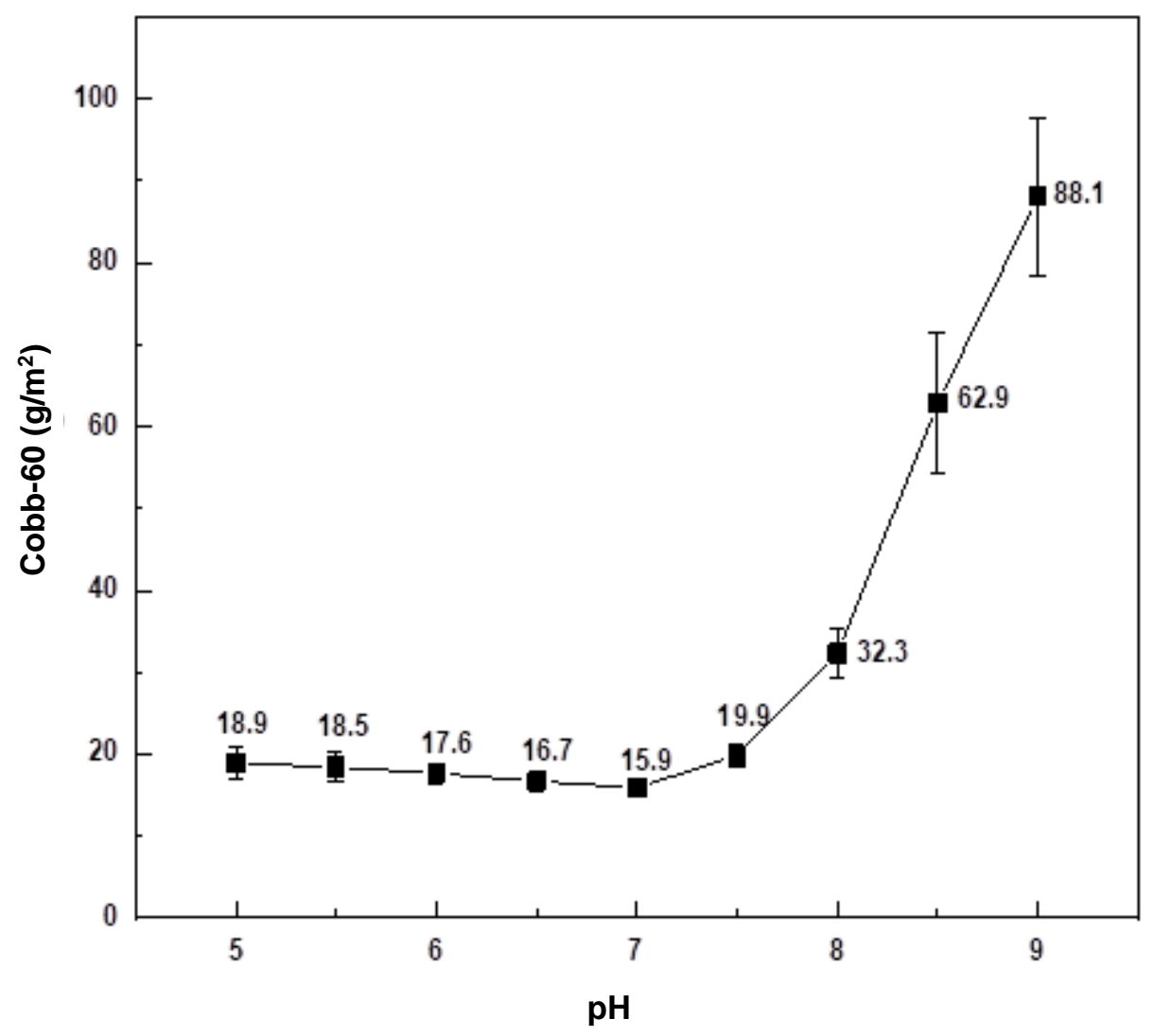

Fig. 7. Effect of $\mathrm{pH}$ on water resistance

In summary, the optimum sizing conditions were as follows: The SRP sizing agent dosage was $1.0 \%$ of the absolute dry pulp mass, the $\mathrm{Al}_{2}\left(\mathrm{SO}_{4}\right)_{3}$ dosage was $1.0 \%$ of the absolute dry pulp mass, and the CPAM dosage was $0.15 \%$ of the dry pulp mass at a $\mathrm{pH}$ of 7.0. For the paper obtained under these conditions, Cobb-60 was $15.9 \mathrm{~g} / \mathrm{m}^{2}$, the burst index was $2.95 \mathrm{kPa} \cdot \mathrm{m}^{2} / \mathrm{g}$, the tear index was $16.51 \mathrm{mN} \cdot \mathrm{m}^{2} / \mathrm{g}$, and the tensile index was 43.06 $\mathrm{N} \cdot \mathrm{m} / \mathrm{g}$.

\section{Confirming the SRP Treatment Effects on Water Resistance Using Dynamic Contact Angle Measurement}

After application of the SRP sizing agent, the dynamic contact angle (DCA) of a water droplet with the paper surface was tested (Fig. 8). The DCA of the treated papers (approximately $125^{\circ}$ ) was much greater than the DCA of the control samples (less than $90^{\circ}$ ), indicating that the applied sizing system successfully decreased the surface free energy of the fibers. The results showed that the paper treated under the optimal conditions required more time for the water droplet to absorb than did the control paper. In the control paper, the contact angle drastically decreased in only $5 \mathrm{~s}$. 

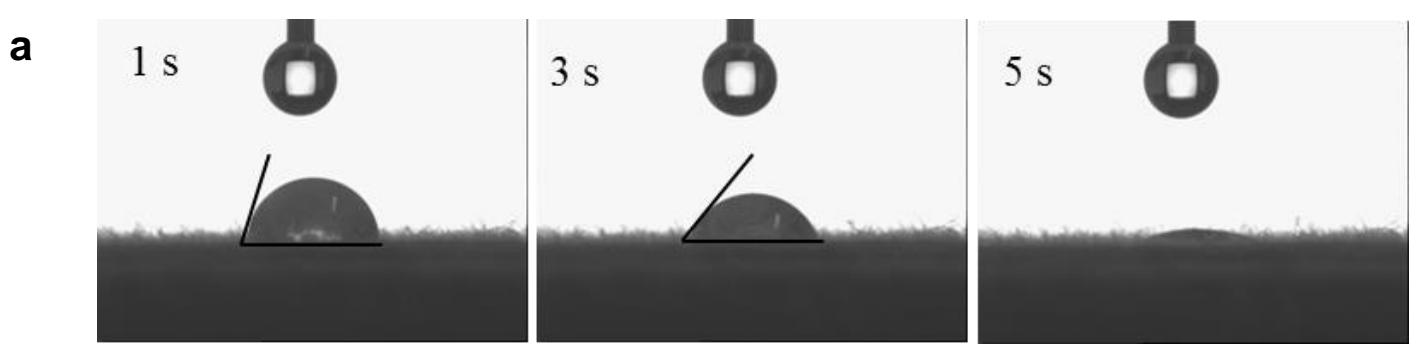

b

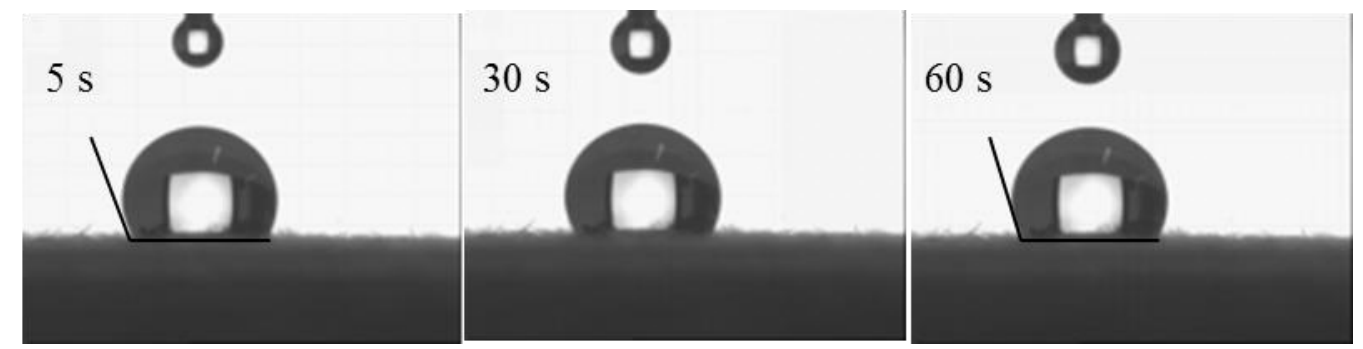

Fig. 8. The differences in the contact angles of the water droplets with the surfaces between (a) the control paper and (b) the treated paper (under the optimal conditions)

\section{Confirming the SRP Treatment Effects on Water Resistance Using Scanning Electron Microscopy}

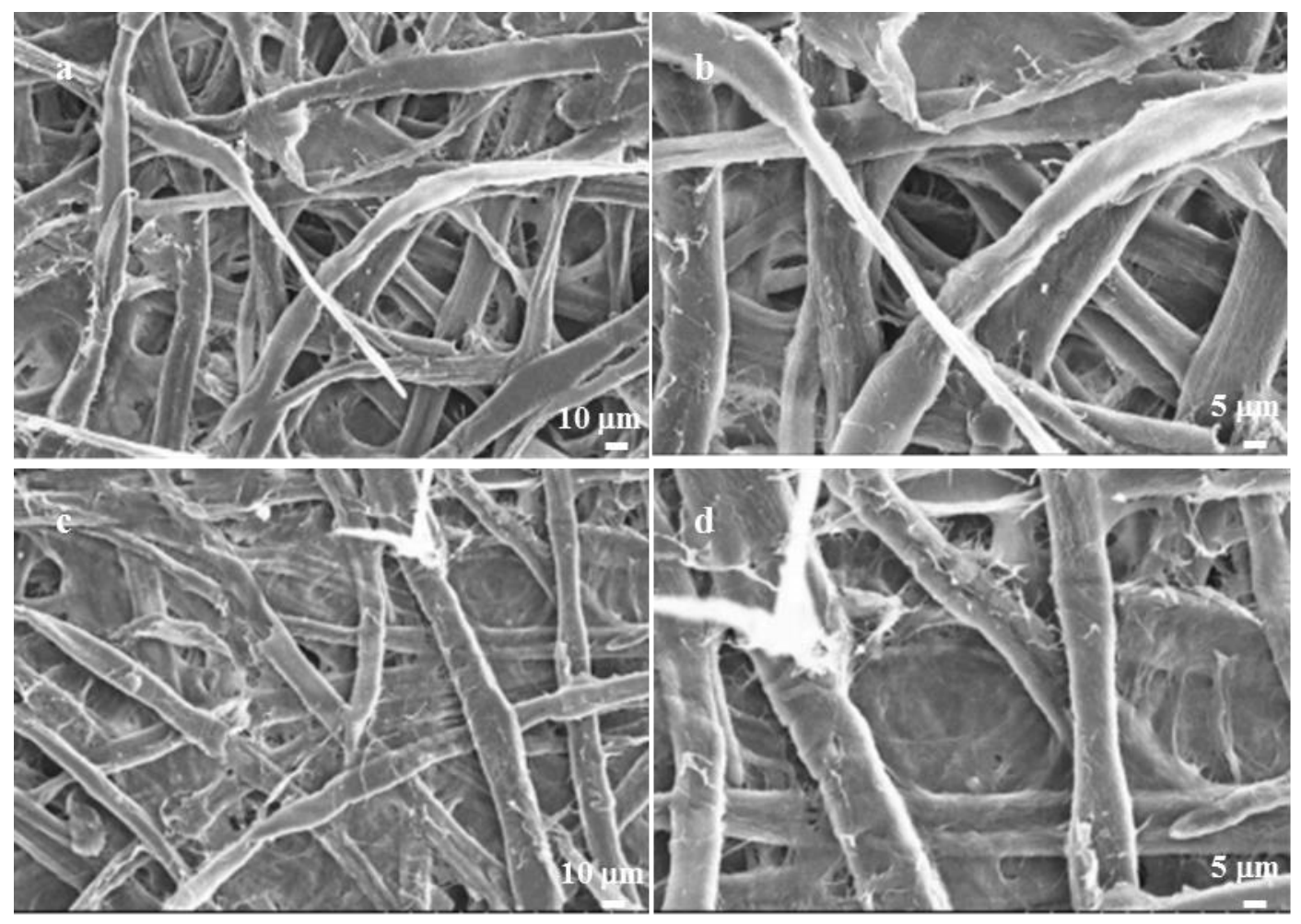

Fig. 9. Scanning electron micrographs of the surfaces of the control paper ( $a$ and $b$ ) and the SRP sizing agent-treated paper ( $c$ and $d$ ) 
Comparison of Fig. 9a and 9b with Fig. 9c and 9d shows that although the SRP sizing agent was used in the internal sizing, there were some layers on the surface of the sized paper. These film layers were formed by the SRP particles adsorbed on the surfaces of the paper fibers being melted during the heating and drying processes. The melted SRP then uniformly flowed on the paper and conferred good hydrophobicity to the paper.

\section{Effect of Calcium Carbonate Dosage on Water Resistance}

Because of the good whiteness of precipitated calcium carbonate $\left(\mathrm{CaCO}_{3}\right)$, it can be used to make high-grade paper varieties. However, its chemical stability is poor, and $\mathrm{CO}_{2}$ is released under acidic conditions. Because the sizing system prepared in this study is in a neutral (alkaline) environment, it can completely tolerate the addition of $\mathrm{CaCO}_{3}$.

As shown in Fig. 10, under the optimal conditions, the $\mathrm{CaCO}_{3}$ dosage was changed from $0 \%$ to $25 \%$. The Cobb-60 level gradually increased with increasing calcium carbonate, but a good sizing degree remained at $15 \%$ calcium carbonate, where the Cobb-60 level was $26.0 \mathrm{~g} / \mathrm{m}^{2}$. This result showed that the SRP sizing agent could tolerate the addition of a certain amount of calcium carbonate.

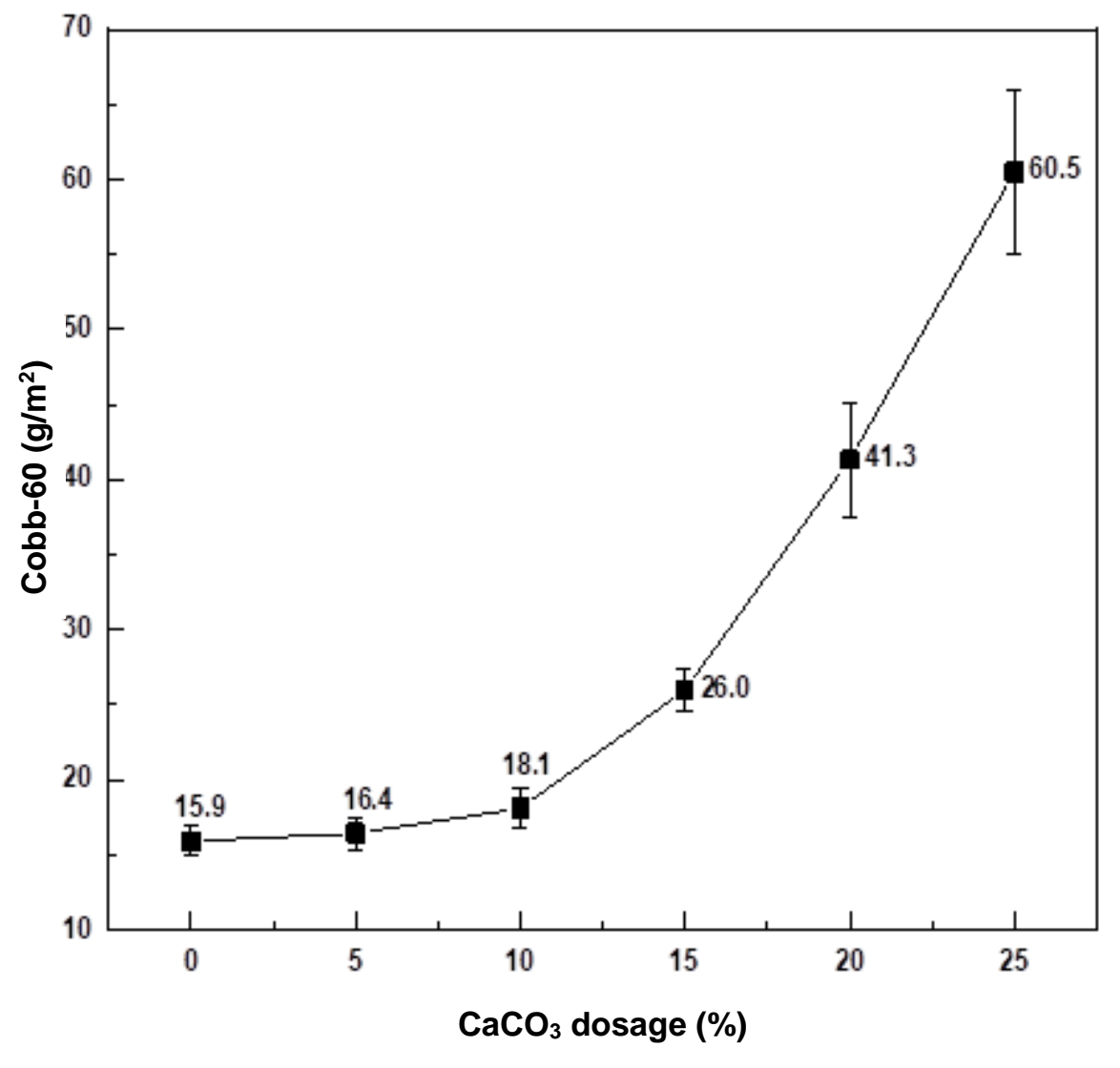

Fig. 10. Effect of $\mathrm{CaCO}_{3}$ dosage on water resistance 


\section{CONCLUSIONS}

1. Emulsification of soybean oil rosin-based polyester (SRP) with $8 \%$ ethoxylated nonylphenol sulfosuccinic acid half ester disodium salt yielded a bluish-white emulsion with an average particle size of $0.224 \mu \mathrm{m}$.

2. The SRP sizing agent was found to be favorable for neutral sizing: The SRP sizing agent dosage was $1.0 \%$ of the absolute dry pulp mass, the $\mathrm{Al}_{2}\left(\mathrm{SO}_{4}\right)_{3}$ dosage was $1.0 \%$ of the absolute dry pulp mass, and the CPAM dosage was $0.15 \%$ of the dry pulp mass, preferably at a $\mathrm{pH}$ of 7.0. For the paper obtained under these conditions, Cobb-60 was $15.9 \mathrm{~g} / \mathrm{m}^{2}$, the burst index was $2.95 \mathrm{kPa} \cdot \mathrm{m}^{2} / \mathrm{g}$, the tear index was $16.51 \mathrm{mN} \cdot \mathrm{m}^{2} / \mathrm{g}$, and the tensile index was $43.06 \mathrm{~N} \cdot \mathrm{m} / \mathrm{g}$.

3. Under the optimal conditions, the contact angle of the paper was approximately $125^{\circ}$. Scanning electron microscopy showed that some compact film layers had formed on the surface of the paper, indicating that the SRP had good sizing performance.

4. The SRP sizing agent allowed the addition of $\mathrm{CaCO}_{3}$. When the $\mathrm{CaCO}_{3}$ dosage was $15 \%$, the Cobb-60 of the paper was $26.0 \mathrm{~g} / \mathrm{m}^{2}$.

\section{ACKNOWLEDGMENTS}

This research was financially supported by grants from the National Key R\&D Program of China (Grant No. 2016YFD0600804) and the National Key Technology R\&D Program of China (Grant No. 2015BAD15B08).

\section{REFERENCES CITED}

Hamzeh, Y., Ekhtera, M. H., Hubbe, M. A., Izadyar, S., and Pourtahmasi, K. (2008). "Effects of process variables on poly-aluminum chloride (PAC)-rosin sizing performance under neutral papermaking conditions," Industrial \& Engineering Chemistry Research 47(13), 4302-4307. DOI: 10.1021/ie800107x

Hubbe, M. A. (2007). "Paper's resistance to wetting - A review of internal sizing chemicals and their effects," BioResources 2(1), 106-145. DOI:

10.15376/biores.2.1.106-145

ISO 535 (2014). "Paper and board -- Determination of water absorptiveness -- Cobb method," International Organization for Standardization, Geneva, Switzerland.

ISO 536 (2012). "Paper and board -- Determination of grammage," International Organization for Standardization, Geneva, Switzerland.

ISO 1924-2 (2008). "Paper and board -- Determination of tensile properties -- Part 2: Constant rate of elongation method $(20 \mathrm{~mm} / \mathrm{min})$," International Organization for Standardization, Geneva, Switzerland.

ISO 1974 (2012). "Paper -- Determination of tearing resistance -- Elmendorf method," International Organization for Standardization, Geneva, Switzerland.

ISO 2758 (2014). "Paper -- Determination of bursting strength,” International Organization for Standardization, Geneva, Switzerland.

Katz, G., House, L. W., Alexander, Sr., D. E., Sowers, S. L., and Marton, J. (2003). 
“Internal paper sizing improvements," U. S. Patent No. 6540877.

Kitaoka, T., Isogai, A., and Onabe, F. (2000). "Rosin sizing of pulps modified by TEMPO-mediated oxidation," Nordic Pulp \& Paper Research Journal 15(3), 177 -

182. DOI: 10.3183/npprj-2000-15-03-p177-182

Kitaoka, T., Isogai, A., and Onahe, F. (1997). "Sizing mechanism of emulsion rosin sizealum systems," Nordic Pulp \& Paper Research Journal 12(1), 26-31. DOI: 10.3183/npprj-1997-12-01-p026-031

Kitaoka, T., Yamamoto, H., Nishino, R., and Tanaka, H. (2001). "Two-dimensional XPS analysis of rosin distribution in paper sheets tub-sized with dispersed rosin size,” Sen’i Gakkaishi 57(7), 212-219. DOI: 10.2115/fiber.57.212

Lindström, T., and Larsson, P. T. (2008). "Alkyl ketene dimer (AKD) sizing - A review," Nordic Pulp \& Paper Research Journal 23(2), 202-209. DOI: 10.3183/npprj-200823-02-p202-209

Liu, W., Chen, Z., and Duan, H. (2006). "Sizing behavior of cationic dispersed rosin-ester on cellulose fibers," Nordic Pulp \& Paper Research Journal 21(5), 586-590. DOI: 10.3183/npprj-2006-21-05-p586-590

Matsushita, Y., Iwatsuki, A., and Yasuda, S. (2004). "Application of cationic polymer prepared from sulfuric acid lignin as a retention aid for usual rosin sizes to neutral papermaking," Journal of Wood Science 50(6), 540-544. DOI: 10.1007/s10086-0030602-2

Mattsson, R., Sterte, J., and Ödberg, L. (2002). "Sizing with pre-flocculated alkylketene dimer (AKD) dispersions," Nordic Pulp \& Paper Research Journal 17(3), 240-245. DOI: 10.3183/npprj-2002-17-03-p240-245

Ozaki, Y., and Sawatari, A. (1997). "Surface characterization of a rosin sizing agent in paper by means of EPMA, ESCA and TOF-SIMS," Nordic Pulp \& Paper Research Journal 12(4), 260-266. DOI: 10.3183/npprj-1997-12-04-p260-266

Rahmaninia, M., Javid, E., and Varshoei, A. (2016). "Process variables and the performance of cationic rosin as an internal sizing agent in recycled corrugated container pulp," BioResources 11(2), 5333-5342. DOI: 10.15376/biores.11.2.53335342

Seppänen, R., Tiberg, F., and Valignat, M.-P. (2000). "Mechanism of internal sizing by alkyl ketene dimers (AKD): The role of the spreading monolayer precursor and autophobicity," Nordic Pulp \& Paper Research Journal 15(5), 452-458. DOI: 10.3183/npprj-2000-15-05-p452-458

Varshoei, A., Javid, E., Rahmaninia, M., and Rahmany, F. (2013). "The performance of alkylketene dimer (AKD) for the internal sizing of recycled OCC pulp," Lignocellulose 2(1), 316-326.

Wang, F., and Tanaka, H. (2000). "Aminated poly-N-vinylformamide as a modern retention aid of alkaline paper sizing with acid rosin sizes," Journal of Applied Polymer Science 78(10), 1805-1810. DOI: 10.1002/10974628(20001205)78:10<1805::aid-app120>3.0.co;2-x

Wang, F., Kitaoka, T., and Tanaka, H. (2003). "Supramolecular structure and sizing performance of rosin-based emulsion size microparticles," Colloids and Surfaces A: Physicochemical and Engineering Aspects 221(1-3), 19-28. DOI: 10.1016/s09277757(03)00098-0

Wang, F., Tanaka, H., Kitaoka, T., and Hubbe, M. A. (2000). "Distribution characteristics of rosin size and their effect on the internal sizing of paper," Nordic Pulp \& Paper Research Journal 15(5), 416-421. DOI: 10.3183/npprj-2000-15-05- 


$$
\text { p416-421 }
$$

Wang, F., Wu, Z., and Tanaka, H. (1999). "Preparation and sizing mechanisms of neutral rosin size II: Functions of rosin derivatives on sizing efficiency," Journal of Wood Science 45(6), 475-480. DOI: 10.1007/bf00538956

Wu, Z.-H., Chen, S.-P., and Tanaka, H. (1997). "Effects of polyamine structure on rosin sizing under neutral papermaking conditions," Journal of Applied Polymer Science 65(11), 2159-2163. DOI: 10.1002/(sici)1097-4628(19970912)65:11<2159::aidapp12>3.0.co;2-Z

Xu, Y.-Z., Chen, Y.-X., and Zhao, Z.-D. (2019). "Synthesis and characterization of waterborne soybean oil-rosin based hyperbranched polyester," Fine Chemicals 36(7), 1294-1300. DOI: 10.13550/j.jxhg.20180886

Yao, K., Wang, J., Zhang, W., Lee, J. S., Wang, C., Chu, F., He, X., and Tang, C. (2011). "Degradable rosin-ester-caprolactone graft copolymers," Biomacromolecules 12(6), 2171-2177. DOI: $10.1021 / \mathrm{bm} 200460 \mathrm{u}$

Article submitted: July 19, 2019; Peer review completed: September 18, 2019; Revised version received: September 18, 2019; Accepted: September 29, 2019; Published:

October 4, 2019.

DOI: $10.15376 /$ biores.14.4.9183-9197 